\title{
OPERATION OF BASED IMPEDANCE PROTECTION NUMERICAL RELAY WITH STATCOM FACTS DEVICES
}

\author{
Omar Noureldeen \\ Faculty of Engineering, South Valley University, Qena, Egypt \\ E-mail : omarnoureldeen@yahoo.com
}

(Received May 21, 2009 Accepted July 13, 2009).

\begin{abstract}
This paper presents a study of the impacts of the Flexible AC Transmission Systems (FACTS) devices on the transmission line impedance measured by numerical impedance protection relay when applied to protect a shunt compensated transmission line. Most of the FACTS devices are installed on existing transmission lines to enhance their capacity and performance. The Static Synchronous Compensator (STATCOM) is a shunt device of the FACTS family using power electronics to control power flow and improve transient stability on power grids. This paper investigates the effect of STATCOM operation conditions during voltage fluctuations and faults on the impedance measured by numerical impedance relay. Matlab with SimPowerSystems toolbox is used to model and simulate a $500 \mathrm{KV}, 300 \mathrm{Km}$ shunt compensated transmission line. The effects of different fault types and different voltage fluctuation cases on the numerical impedance relay are investigated of compensated and uncompensated transmission line.
\end{abstract}

KEYWORDS: FACTS, STATCOM, Voltage fluctuation, Impedance relay.

\section{INTRODUCTION}

Impedance based protection relays are widely used as the main protection devices for transmission lines. They operate based on impedance measurement at the relaying point, which is affected by several factors. Impedance relay utilizes a combination of the voltage and current signals at the relay location to determine the apparent impedance as seen by the relay under all conditions. One of numerical distance relay algorithm is based on estimation of transmission line parameters as impedance and reactance to calculate the fault location. This algorithm utilizes the voltage and current signals at relay location to estimate the apparent impedance of transmission line [1]. When a fault occurs on a transmission line, the voltage on the line depresses and, therefore, the line charging currents are minimal. If the line charging is neglected, the line can be modeled as a resistance and inductance connected in series [2].

Recent development of power electronics introduces the use of FACTS devices in power system. The shunt FACTS devices are used for controlling transmission line voltage, power flow, reducing reactive losses, and damping of power system oscillations for high power system stability and reliability. They can be connected to transmission line in series or shunt. The Static Synchronous Compensator (STATCOM) is one of these types and is connected in shunt. The STATCOM consists of three-phase sets of several gate turn off switched based values (GTOs) and a DC 
link capacitor. The STATCOM regulates the voltage at its terminals by controlling the amount of reactive power injected into or absorbed from the power system $[3,4,5,6,7]$. The STATCOM is widely connected at the midpoint of transmission line or at a heavy load area to maintain the connecting point voltage [8].

There exists literature on the performance of the protection for a power system containing FACTS devices $[9,10]$. The study presented in [9] studied the impact of STATCOM on impedance protection relays under normal operating conditions as well as for fault conditions under different loading levels. The study in [10] demonstrates that the presence of FACTS devices on a transmission line will affect the trip boundary of distance relay, and both the parameters of the FACTS device and its location have impact on the trip boundary. In this paper, the impacts of STATCOM operation conditions during voltage fluctuation and fault on the estimated transmission line impedances are studied. The impedances are measured by left and right numerical relays located at sending and receiving end respectively.

\section{CASE STUDY}

\subsection{System Simulation}

Figure 1 shows a single line diagram of a midpoint compensated transmission line under study. A simulation model of $500 \mathrm{KV}, 300 \mathrm{Km}$ transmission line is used to produce voltage and current waveforms for different types of faults and voltage fluctuations on transmission line.

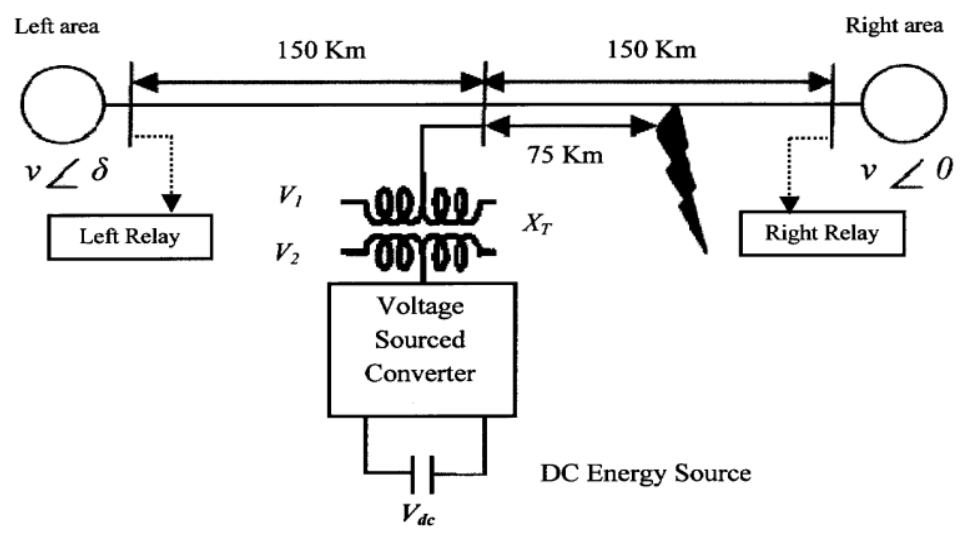

Fig. (1) Midpoint compensated transmission line

The transmission line joints two areas system (left area and right area), the direction of real power is from the left area to the right area with power angle $\delta$ equals $18^{\circ}$. The transmission line is modeled by four $\pi$ sections and the protection relay is located at sending and receiving ends to be studied. A 100 Mvar STATCOM is connected to the transmission line midpoint via a coupling transformer. It is able to change the power flow in the system by controlling the amount of reactive power injected into or absorbed from the power system to regulate the voltage profile of the bus to which it is connected. 


\subsection{STATCOM Operation and Control}

The reactive power transfer via a coupling transformer is controlled by the following equation:

$$
Q=\frac{V_{1}\left(V_{1}-V_{2} \cos \delta_{T}\right)}{X_{T}}
$$

Where $V_{1}$ is the bus voltage, $V_{2}$ is the voltage of voltage sourced converter, $X_{T}$ is the reactance of the coupling transformer and $\delta_{T}$ is the phase difference between the voltages $V_{1}$ and $V_{2}$. In a steady state operation condition, the line voltage $V_{1}$ and the generated voltage $V_{2}$ are in phase, and $\left(\delta_{T}=0\right)$, the amount of reactive power is given by

$$
Q=\frac{V_{1}\left(V_{1}-V_{2}\right)}{X_{T}}
$$

When the transmission line voltage is increased, the STATCOM operates in inductive mode to absorb reactive power from transmission line. When the voltage is decreased the STATCOM operates in capacitive mode to generate reactive power to inject it into the transmission line.

Figure 2 shows the block diagram of the STATCOM controller. The fundamental component of the generated voltage $V_{2}$ is controlled by varying the DC bus voltage. The STATCOM control system task is to increase or decrease the capacitor DC voltage, so that the generated voltage $V_{2}$ has the correct amplitude for the required reactive power. During steady-state operation, the STATCOM control system must keep the generated voltage $V_{2}$ in phase with the system voltage $V_{1}$ except a small phase shift is allowed for active power required by transformer and inverter losses. The voltage and current measurement systems compute the positive sequence components of the STATCOM voltage and current respectively using phase-to-dq transformation. The voltage regulator block is a PI controller which computes the reactive current reference $I_{q_{-} \text {ref }}$ which uses the measured voltage mean value $V_{\text {mean }}$ and reference voltage value $V_{\text {ref }}$. The current regulator block is a PI controller which computes the phase shift angle of the inverter voltage with respect to system voltage. For example, when the system voltage $V_{\text {mean }}$ decreases than $V_{\text {ref }}$, the voltage regulator output is a positive $I_{q_{-} r e f}$. Then the current regulator will increase the phase shift angle lag inverter voltage with respect to system voltage to generate more capacitive reactive power.

\subsection{Apparent Impedance Calculation}

When a fault occurs on a transmission line, the line charging currents are minimal and they can be neglected. In this case, the transmission line is modeled by series R-L circuit. There are two advantages of this model. The first advantage is that it measures the inductance of the line from the relay location to the fault, this parameter is independent on the system frequency and, therefore, the measurements are valid at the 
nominal as well as the off-nominal frequencies. The second advantage is that the DC offset in the current does not affect the measurements.

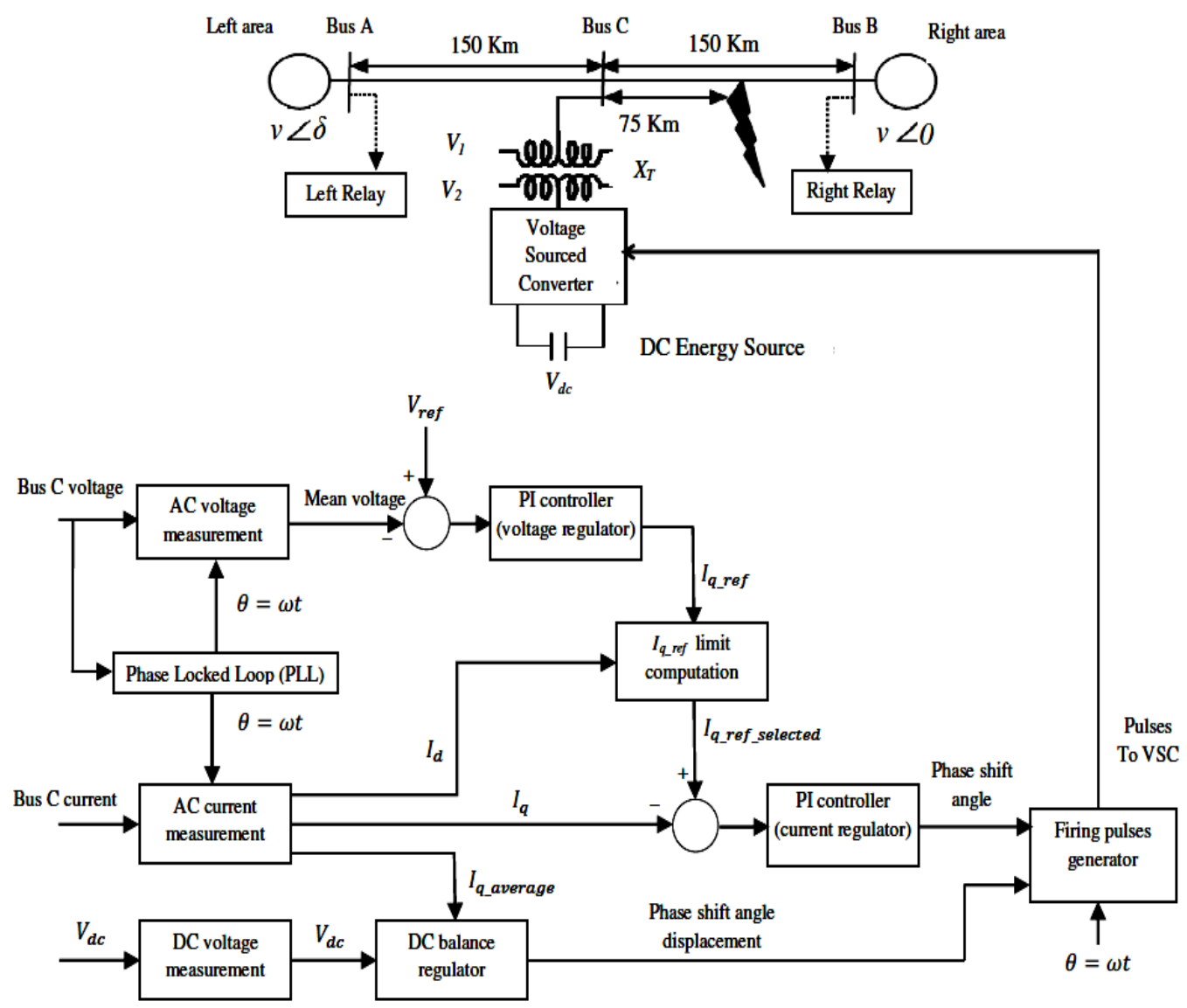

Fig. (2) STATCOM control system used in the simulation of the case study.

The voltage $v$ at the relay location can be expressed as a function of the current $i$ in the circuit as follows [2]:

$$
v=R i+L\left(\frac{d i}{d t}\right)
$$

By applying the differential equation technique, the parameters $R$ and $L$ can be expressed in terms of the current and voltage samples as follows:

$$
\begin{aligned}
& R=\frac{v_{k}\left(i_{k+2}-i_{K}\right)-v_{k+1}\left(i_{k+1}-i_{k-1}\right)}{i_{k}\left(i_{k+2}-i_{K}\right)-i_{k+1}\left(i_{k+1}-i_{k-1}\right)} \\
& L=\left(2 T_{s}\right) \frac{\left(i_{k}\right)\left(v_{k+1}\right)-\left(i_{k+1}\right)\left(v_{k}\right)}{i_{k}\left(i_{k+2}-i_{k}\right)-i_{k+1}\left(i_{k+1}-i_{k-1}\right)}
\end{aligned}
$$

where $k$ is the sampling number and $T_{s}$ is the sampling time interval. Also the apparent impedance $Z$ can be calculated from the estimated values of $R$ and $L$. The voltage $v$ 
and current $i$ signals which are used to calculate the apparent impedance $Z$ depend on the fault type. In case of three phase faults, $v$ represents the line to ground voltage $\left(v_{a g}, v_{b g}\right.$ and $v_{c g}$ ) and $i$ represents the line current $\left(i_{a}, i_{b}\right.$ and $\left.i_{c}\right)$. In case of phase to phase fault, $v$ represents the line to line voltage $\left(v_{a b}, v_{b c}\right.$ and $\left.v_{c a}\right)$ and $i$ represents the delta line current $\left(i_{a b}, i_{b c}\right.$ and $i_{c a}$ ). In case of phase to ground fault, $v$ represents the line to ground voltage $\left(v_{a g}, v_{b g}\right.$ and $\left.v_{c g}\right)$ and $i$ represents the compensated current $\left(i_{a}+K_{0} i_{0}, i_{b}+K_{0} i_{0}\right.$ and $\left.i_{c}+K_{0} i_{0}\right) . i_{0}$ represents zero sequence current, $K_{0}$ represents zero sequence compensation factor, $K_{0}=\left(Z_{0}-Z_{1}\right) / Z_{1}$. The values $Z_{0}$ and $Z_{1}$ represent zero and positive sequence line impedances.

In this paper the impedances are obtained from sampled current and voltage signals at both ends of the transmission line. The voltage and current signals are deduced from the current and voltage waveforms before and after the inception of faults and voltage fluctuations. The conditions of the simulation program are based on the fundamental frequency $(60 \mathrm{~Hz})$, where the sampling frequency is $2000 \mathrm{~Hz},\left(T_{s}=0.5\right.$ $\mathrm{ms}$ ), the total simulated time is $0.5 \mathrm{~s}$ and the digital filter is used to pass frequencies from 60 to $120 \mathrm{~Hz}$.

\section{SIMULATION RESULTS}

\subsection{Effect of Voltage Fluctuation}

To study the effect of voltage fluctuation, a programmable voltage source is used to simulate different voltage fluctuation cases at the left area. Initially the programmable voltage source is set to increase the voltage by $5 \%$ of its nominal value for a period of $100 \mathrm{~ms}$ and let the voltage return to its nominal value for a period of $100 \mathrm{~ms}$. Then, the voltage is decreased by $5 \%$ of its nominal value for a period of $100 \mathrm{~ms}$ and let it return to its nominal value. The simulation is repeated for $10 \%, 15 \%, 20 \%$ and $25 \%$ of voltage fluctuation. During these variations the transmission line impedances are estimated from the voltage and current signals which are obtained from current transformer and voltage transformer which set at left and right sides of transmission line. The variation in estimated impedances is calculated as a percentage error by the following equation:

$$
\text { Percentage error of } Z=\frac{Z_{\text {steady stste }}-Z_{\text {fluctuation }}}{Z_{\text {steady stste }}}(100)
$$

where:

$Z_{\text {steady stste }}$ is the impedance during normal operation.

$Z_{\text {fluctuation }}$ is the impedance value measured by the relay during voltage fluctuation.

The variation of reactive power which is generated by STATCOM during voltage fluctuation of $5 \%$ is shown in Fig. 3. It is noticed that when the voltage is increased, the STATCOM absorbs reactive power from transmission line and when the voltage is decreased, the STATCOM injects reactive power into transmission line.

As shown in Fig. 4, when the voltage at left area is increased by $5 \%$ of its nominal value, the impedance $Z$ which measured by left relay is more than the steady 
state impedance by $6.7 \%$ in case of uncompensated transmission line and it is increased by $8.2 \%$ in case of compensated transmission line. When the voltage is decreased by $5 \%$, the measured impedance $Z$ by left relay is more decreased by $7.9 \%$ than the steady state value in case of uncompensated transmission line and by $10.1 \%$ in case of compensated transmission line. The values of $Z$ measured by right relay in case of voltage increasing by $5 \%$ is decreased by $5.8 \%$ in case of uncompensated transmission line and is decreased by $5 \%$ in case of compensated transmission line. The variations of transmission line impedance $Z$ which are seen by left and right relays during voltage fluctuation by $15 \%$ and $25 \%$ are illustrated in Figs. 5 and 6 respectively.

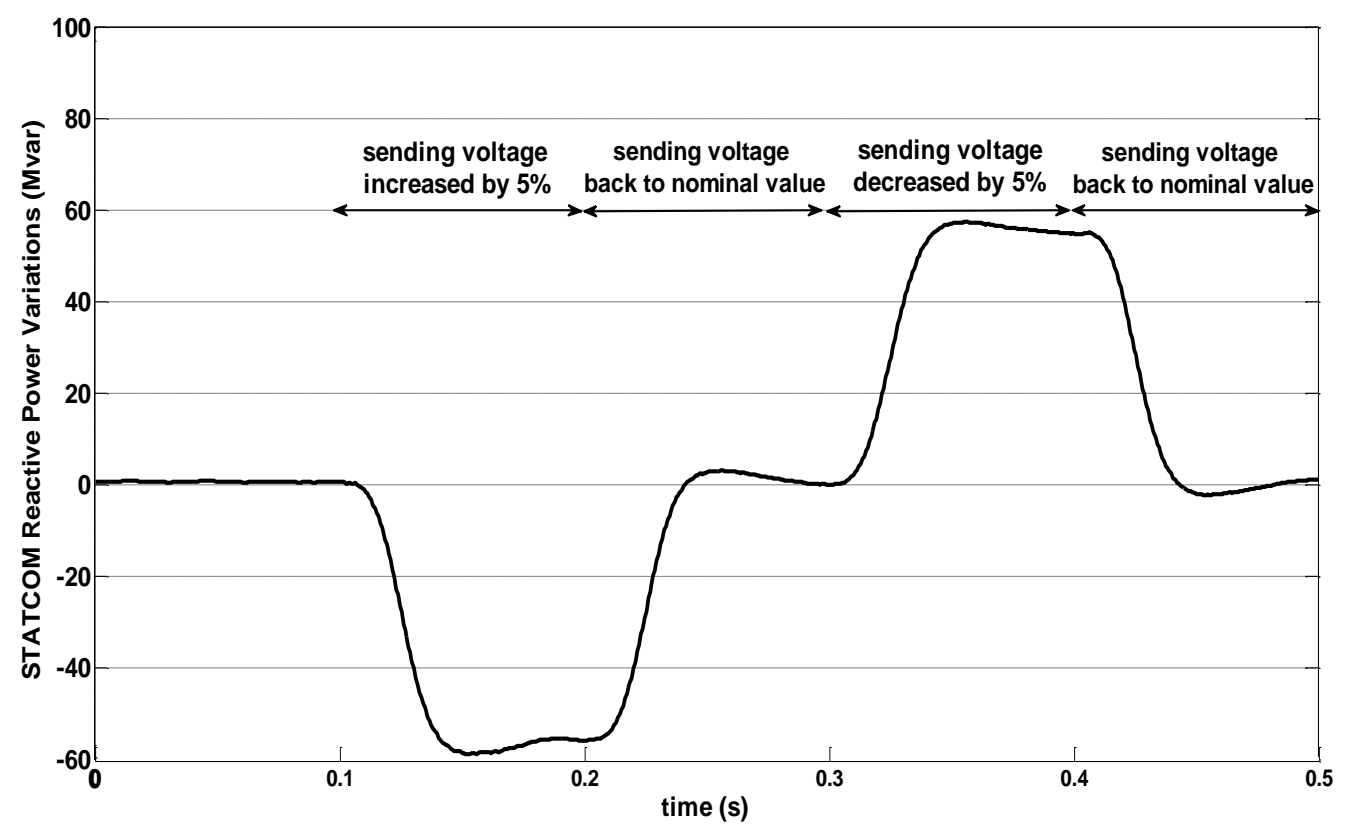

Fig. (3) Reactive power variation of STATCOM during 5\% voltage fluctuation.

Figure 7 shows the percentage error of transmission line impedance measured by the left relay during the voltage fluctuation in two cases with and without STATCOM. Fig. 7(a) illustrates the percentage error variations of measured impedance $Z$ in case of sending end voltage increasing than its nominal value by $5 \%, 10 \%, 15 \%$, $20 \%$ and $25 \%$. The percentage error is calculated based on equation (6). When the measured impedance is increased than the impedance value during normal operation, the percentage error value is negative. When the measured impedance is decreased than the impedance value during normal operation, the percentage error value is positive.

- At $5 \%$ and $10 \%$, the percentage error in $\mathrm{Z}$ is increased in case of compensated transmission line (STATCOM existence) than the case of uncompensated transmission line.

- At $15 \%$, the percentage error of $Z$ is the same in case of compensated and uncompensated transmission line.

- At $20 \%$ and $25 \%$, the percentage error of $\mathrm{Z}$ is decreased in case of compensated transmission line than the case of uncompensated transmission line. 

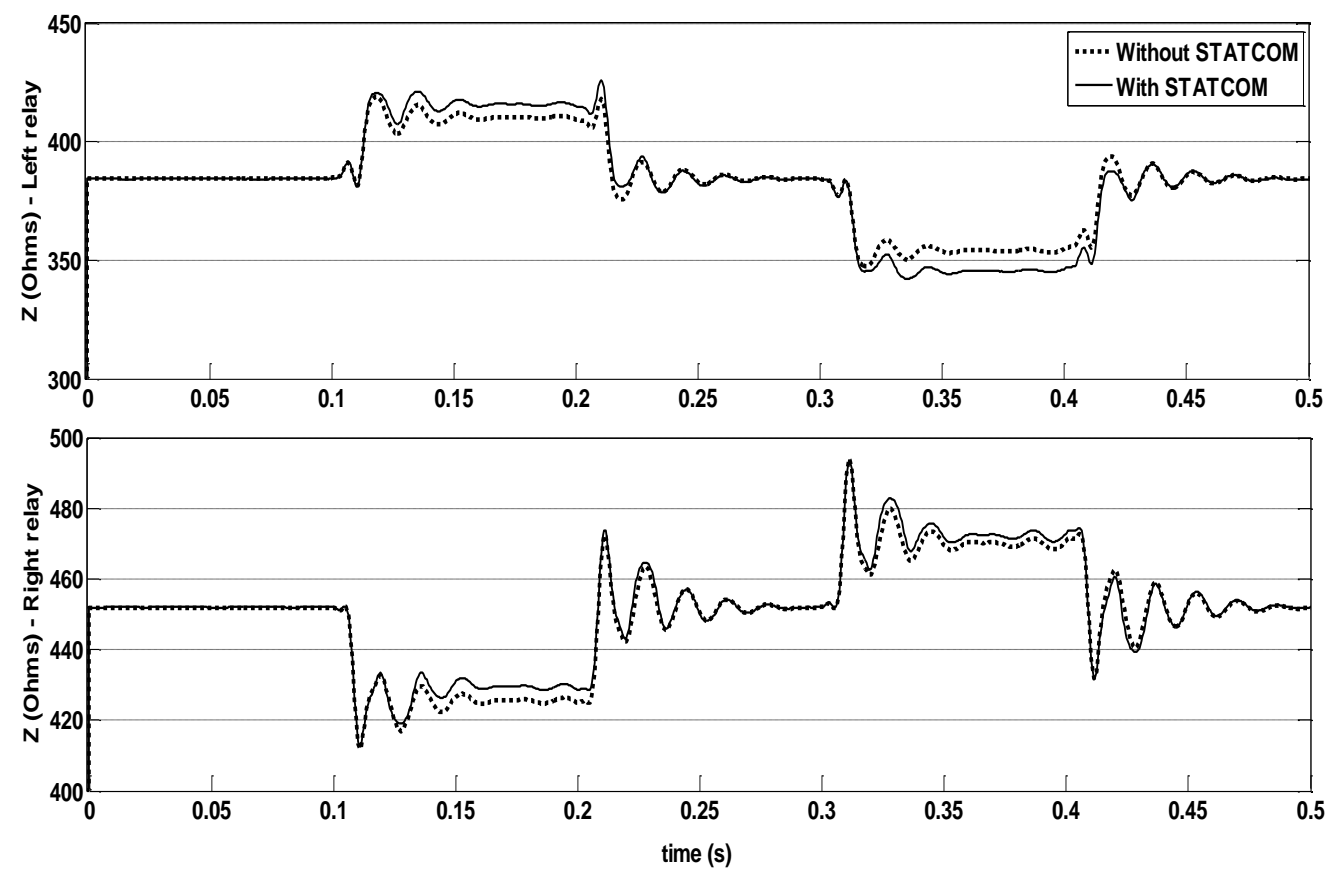

Fig. (4) Transmission line impedances in case of 5\% voltage fluctuations
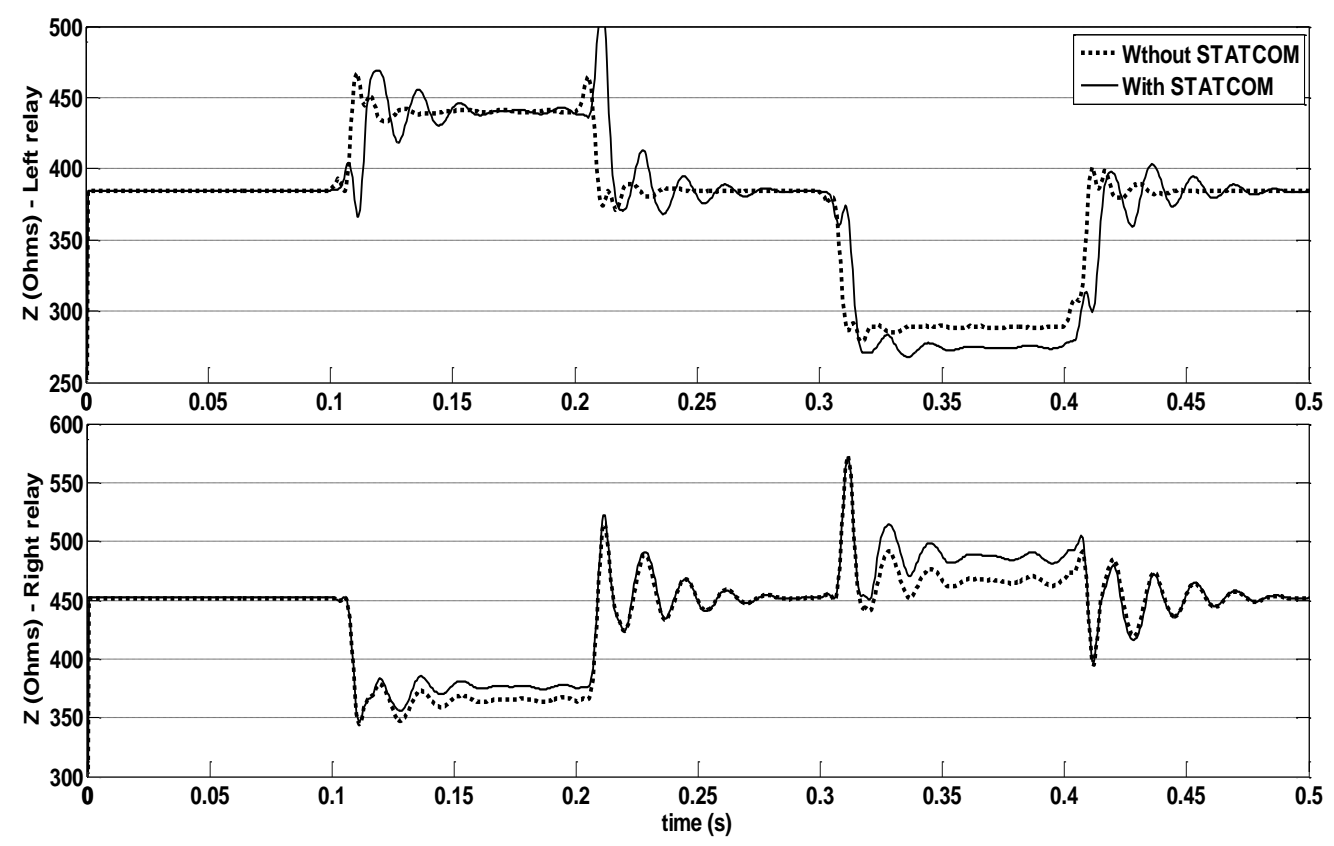

Fig. (5) Transmission line impedances in case of $15 \%$ voltage fluctuations 


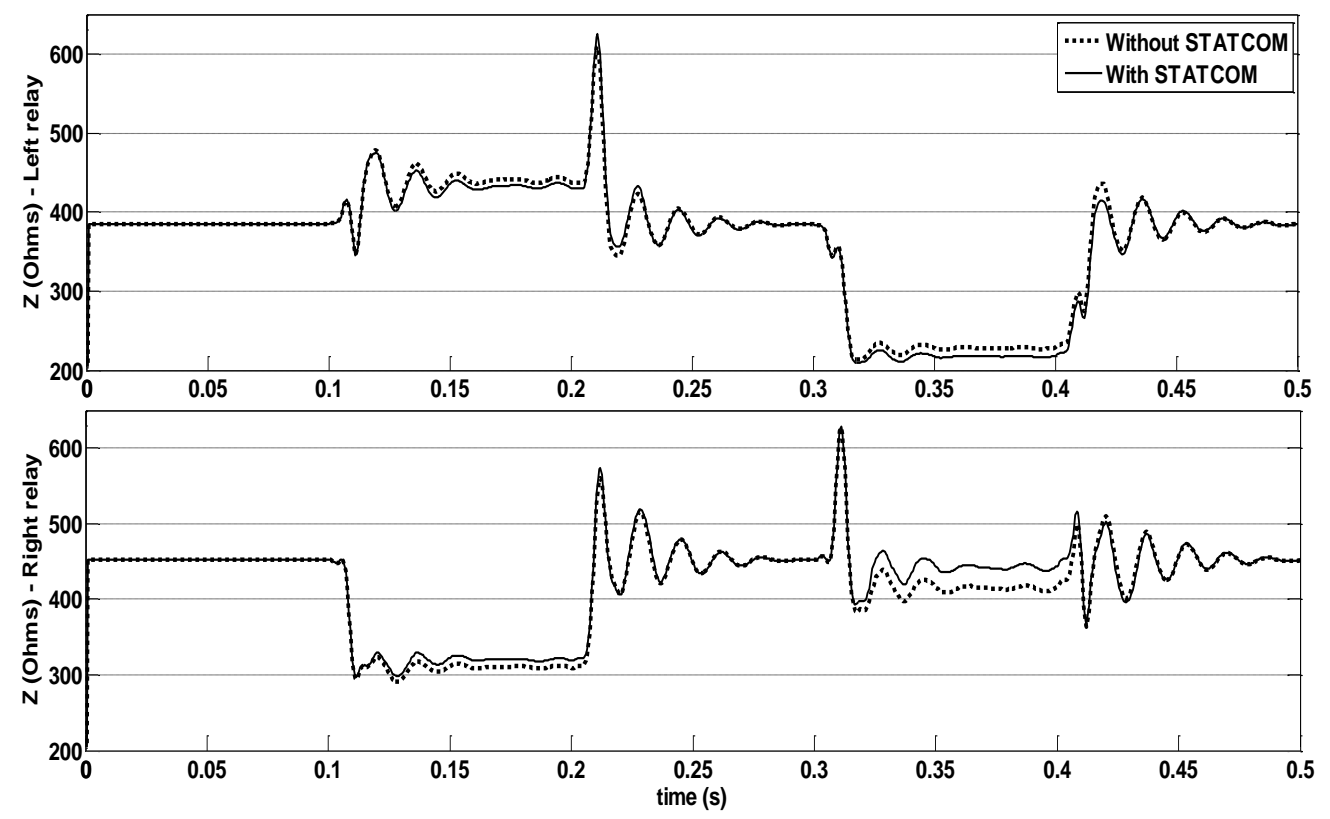

Fig. (6) Transmission line impedances in case of $25 \%$ voltage fluctuations

Figure 7(b) illustrates the percentage error variations of measured impedance $Z$ in case of sending end voltage decreasing than its nominal value by $5 \%, 10 \%, 15 \%$, $20 \%$ and $25 \%$. It is noticed that the percentage error of $Z$ in case of compensated transmission line is more than the case of uncompensated transmission line. Figs. 8(a) and 8 (b) show the variations in transmission line impedance measured by the right relay during the voltage increase and decrease than its nominal value respectively.

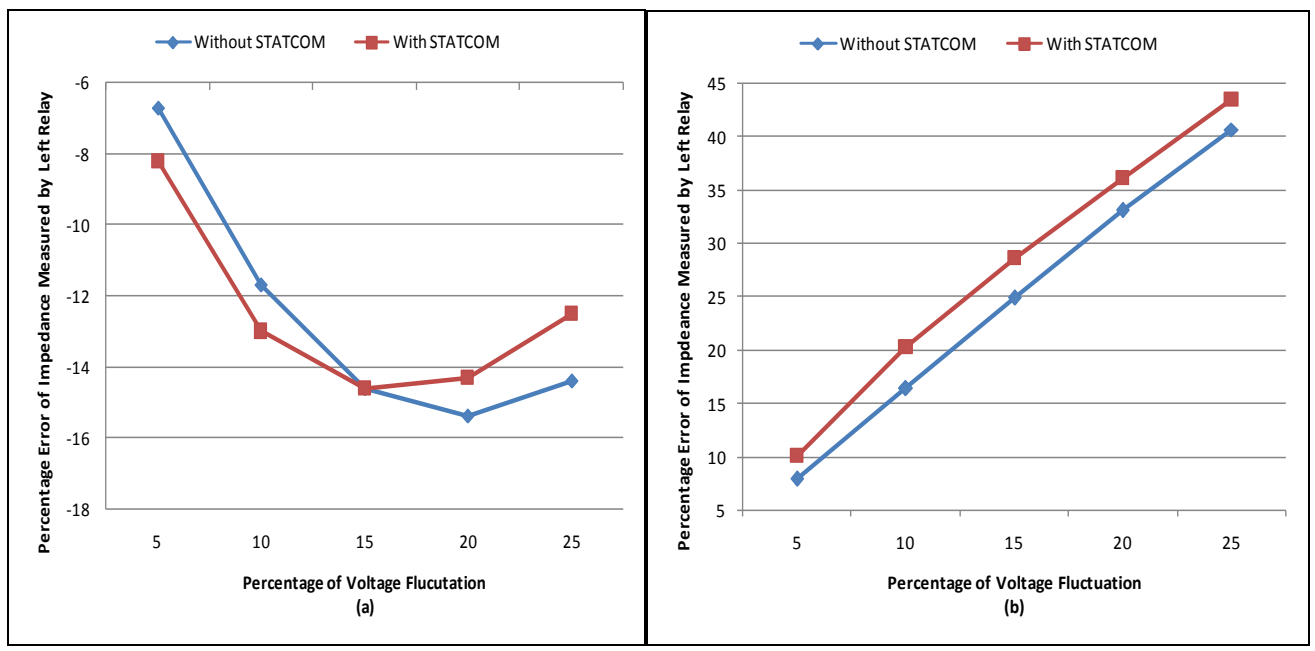

Fig. (7) The percentage error values of measured impedance by left relay versus the sending end voltage fluctuation percentage values

(a) Sending voltage increased (b) Sending voltage decreased 

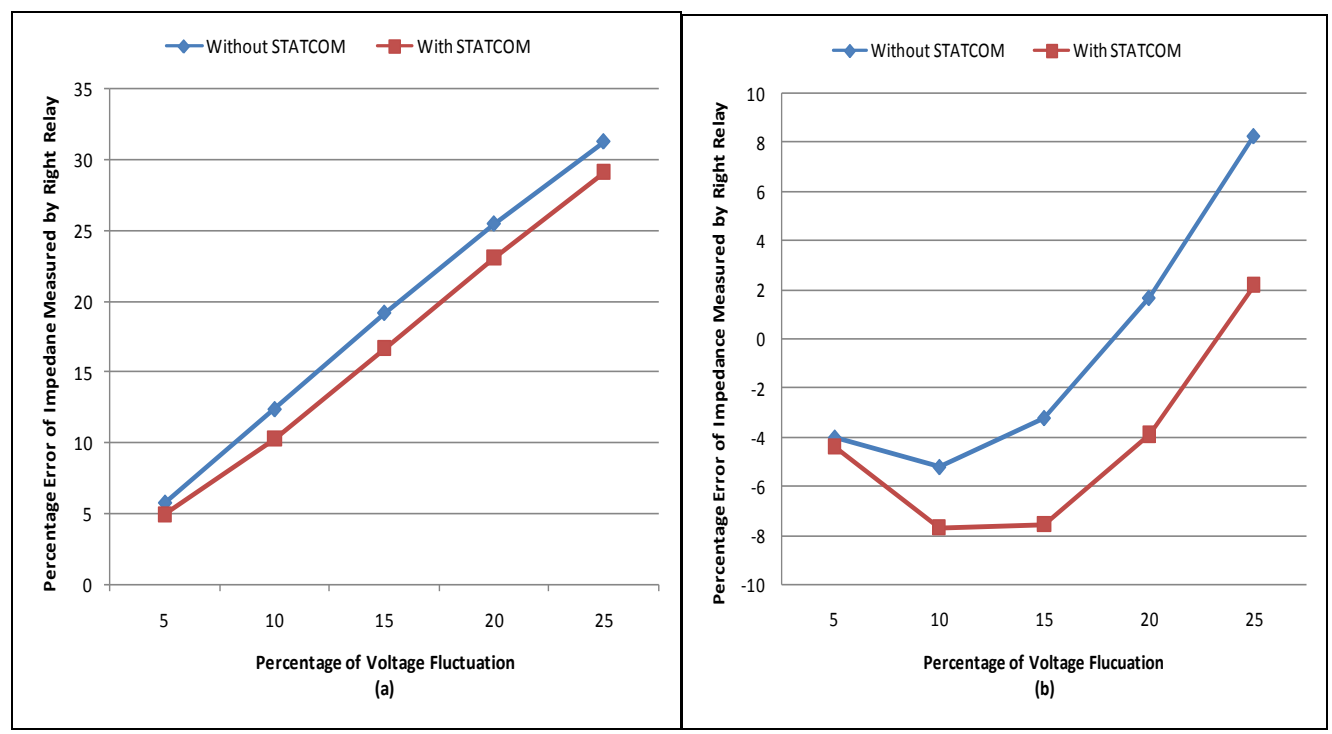

Fig. (8) The percentage error values of measured impedance by right relay versus the sending end voltage fluctuation percentage values

(a) Sending voltage increased (b) Sending voltage decreased

The apparent impedances measured by left and right relays are influenced by the operation characteristics of the STATCOM during different voltage fluctuation cases. Where, the STATCOM operates in inductive mode to absorb reactive power from the transmission line when its voltage is increased. When the transmission line voltage is decreased, the STATCOM operates in capacitive mode to generate reactive power to inject it into the transmission line. The reactive power value varies with the power transfer between the sending and receiving ends to maintain constant voltage at the mid-point.

\subsection{Effect of Faults}

To study the effect of STATCOM on the measured impedance during faults occurrence, the simulation is performed to simulate three types of faults, three phase to ground, double line to ground and single line to ground fault. The fault location at $225 \mathrm{Km}$ from left area (sending end) and the fault duration is $100 \mathrm{~ms}$. Firstly, the simulation is performed without STATCOM. During the simulation, the transmission line impedances are measured by the left and right relays. Secondly, the simulation is repeated during STATCOM connection. Also, the percentage error in estimated impedances values is calculated by (6). The variations of STATCOM reactive power during fault occurrence and after the fault is cleared for different faults are shown in Fig. 9.

As shown in Fig. 10, in case of three phase to ground fault, the effect of STATCOM on the measured impedances is not obvious. Also, in case of double line to ground fault, the variation of estimated impedance during fault is not obvious for 
faulted phases as shown in Fig. 11. But for healthy phase $\mathrm{C}$, the impedance value which is measured by left relay increases by $2.25 \%$ in case of uncompensated transmission line and increases by $3.12 \%$ for compensated transmission line. Also, there are small variations in impedance values which are measured by right relay for healthy phase C. It is found that the impedance value decreases by $0.65 \%$ in case of uncompensated transmission line and increases by $0.1 \%$ for compensated transmission line.

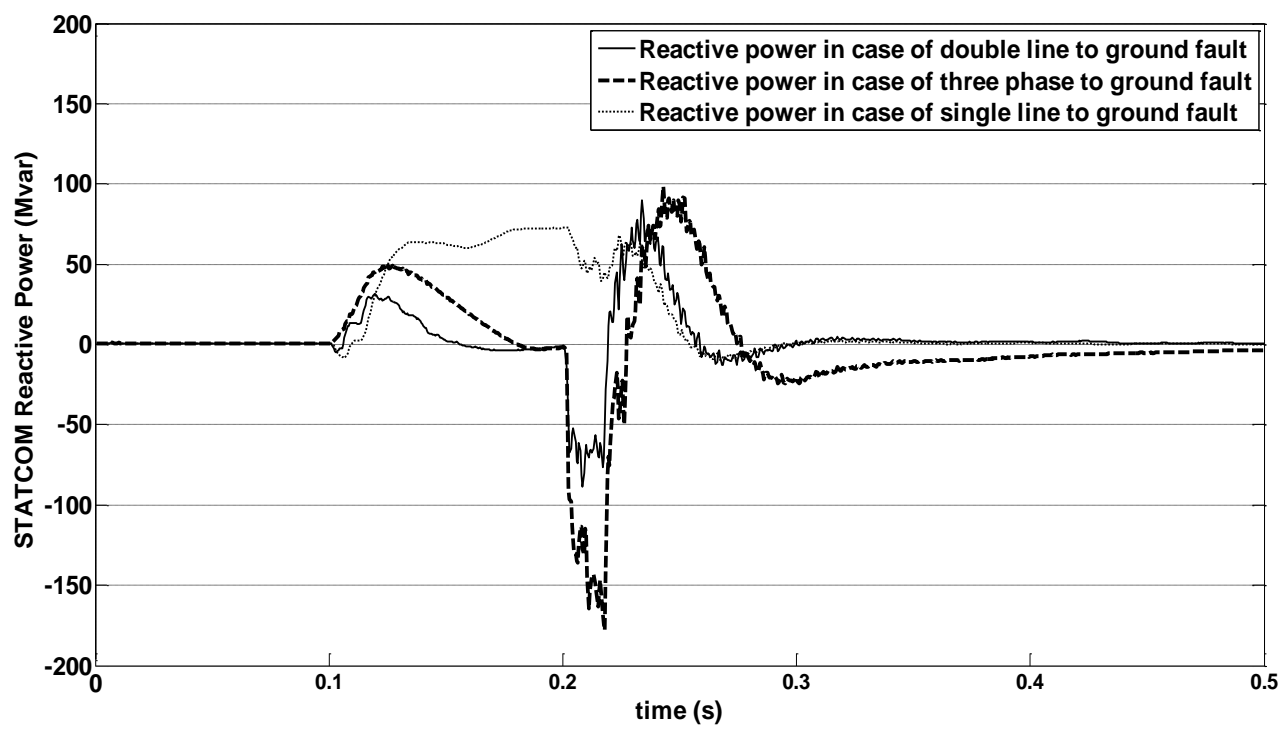

Fig. (9) Reactive power variation of STATCOM during different fault types

In case of single line to ground fault as shown in Fig. 12, the variation of estimated impedances for un-faulted phases B and C is more obvious. It is found that the estimated impedance by left relay for phase B is increased by $12.7 \%$ in case of uncompensated transmission line and is increased by $9 \%$ in case of compensated transmission line. Also, the value of impedance measured by the right relay for phase B indicates that it is increased by $16.89 \%$ in case of uncompensated transmission line and increased by $15 \%$ in case of compensated transmission line.

Regarding the impedances measured by left relay, the STATCOM is in the front of the fault. In this case, the STATCOM boosting the voltage at mid-point of transmission line through injecting a current in quadrature with the line voltage, which is seen as additional impedance by the left relay. The impedance may be either inductive or capacitive, depending on the operation mode of the STATCOM which is located prior to the fault. Regarding the impedances measured by right relay, the STATCOM is behind of the fault. In this case, the STATCOM is not present in the fault loop. Therefore, the effect of STATCOM on the measured impedances is not obvious. For a double line to ground fault, the relay voltage input is line to line voltage and the current is delta line current. Because of the presence of STATCOM, the apparent reactance of healthy phase measured by the left relay increases hence the apparent impedance increases. But unlike the single phase to ground fault the apparent impedance decreases. 


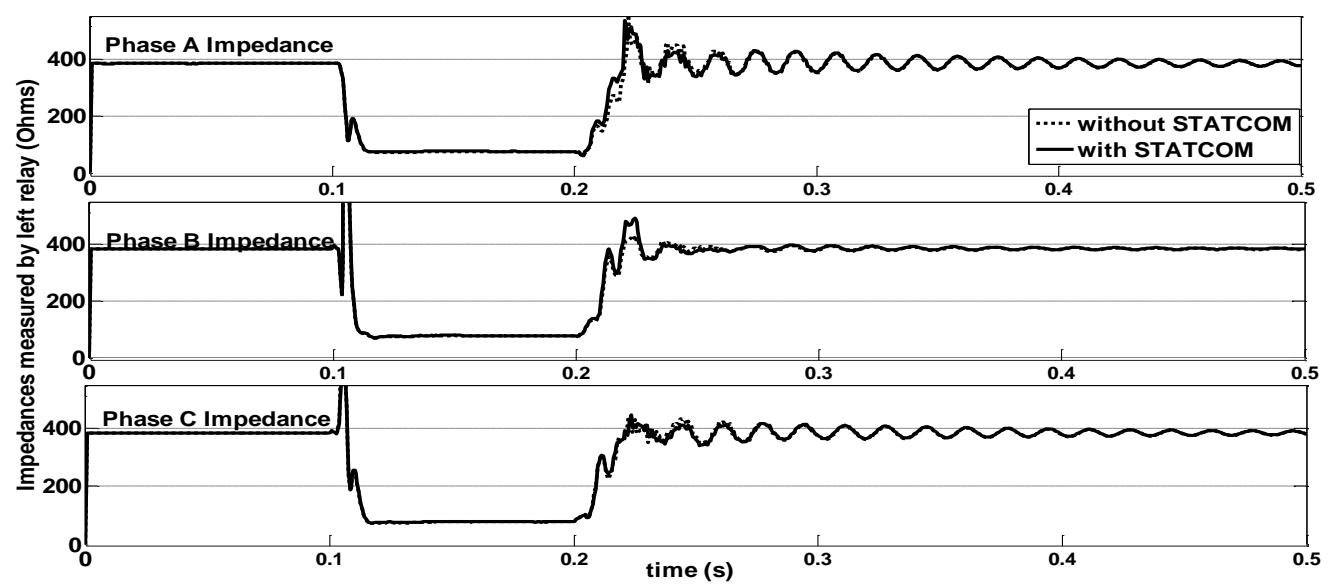

(a)

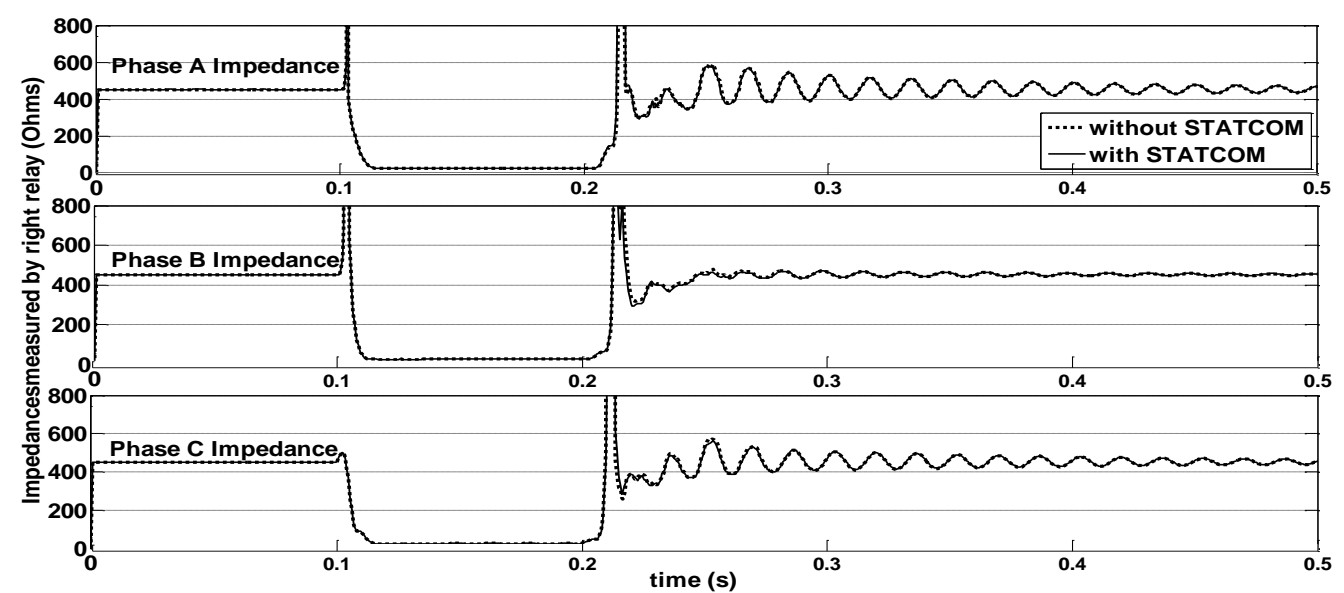

(b)

Fig. (10) Transmission line impedance in case of three phase to ground fault (a) Impedances measured by left relay (b) Impedances measured by right relay

\section{CONCLUSIONS}

During power system fluctuation and faults, the power flow in transmission line is varied due to power injected into or absorbed from transmission line by the Static Synchronous Compensator (STATCOM). During voltage fluctuation, the transmission line impedance which is measured by the numerical impedance relay is affected. It is also varied obviously according to the existence of STATCOM. So, the power caused by STATCOM must be taken into account to increase the accuracy of the measured impedance calculations. During fault occurrence, the power injected into or absorbed from the transmission line depends on the variation of the bus voltage caused by fault. Also, this power depends on the fault type and its location. There are obvious variations in estimated impedance of healthy phase in case of STATCOM existence. That may cause error in discrimination between faulted and healthy phases or fault location estimation. Therefore, the variations in the measured impedance values caused by STATCOM must be taken into account during the application of the fault location determination technique based on measured impedance. 


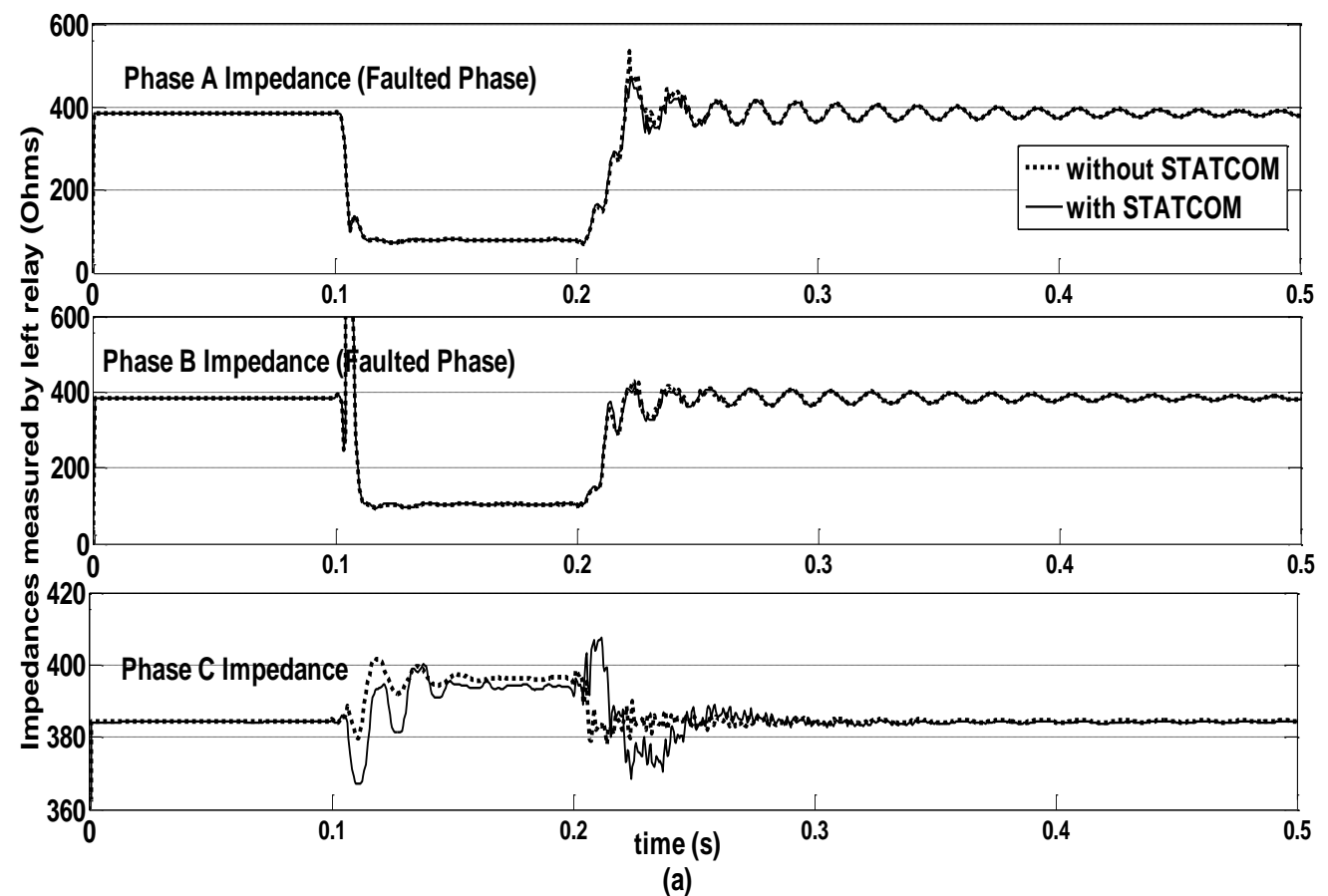

(a)

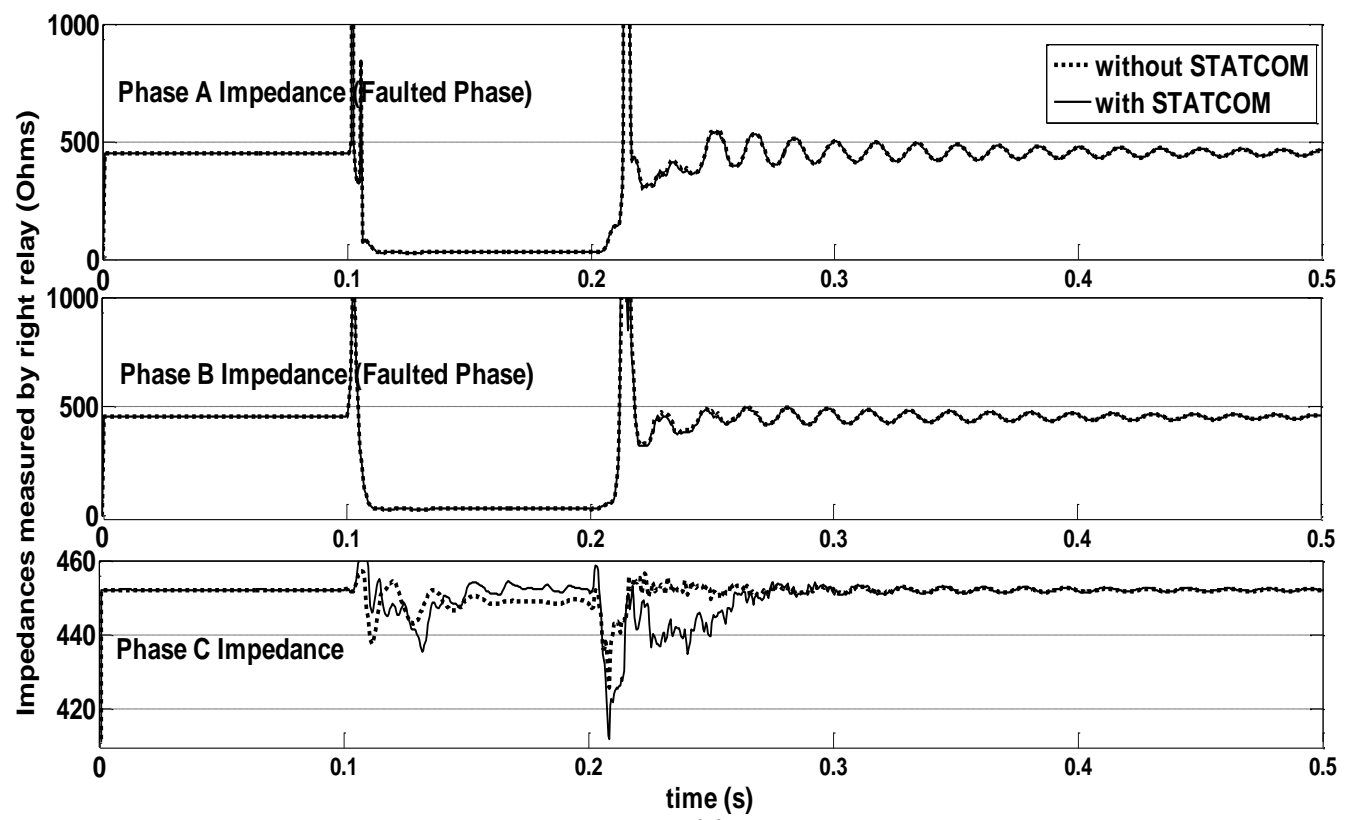

(b)

Fig. (11) Transmission line impedance in case of double phase to ground fault (a) Impedances measured by left relay (b) Impedances measured by right relay 


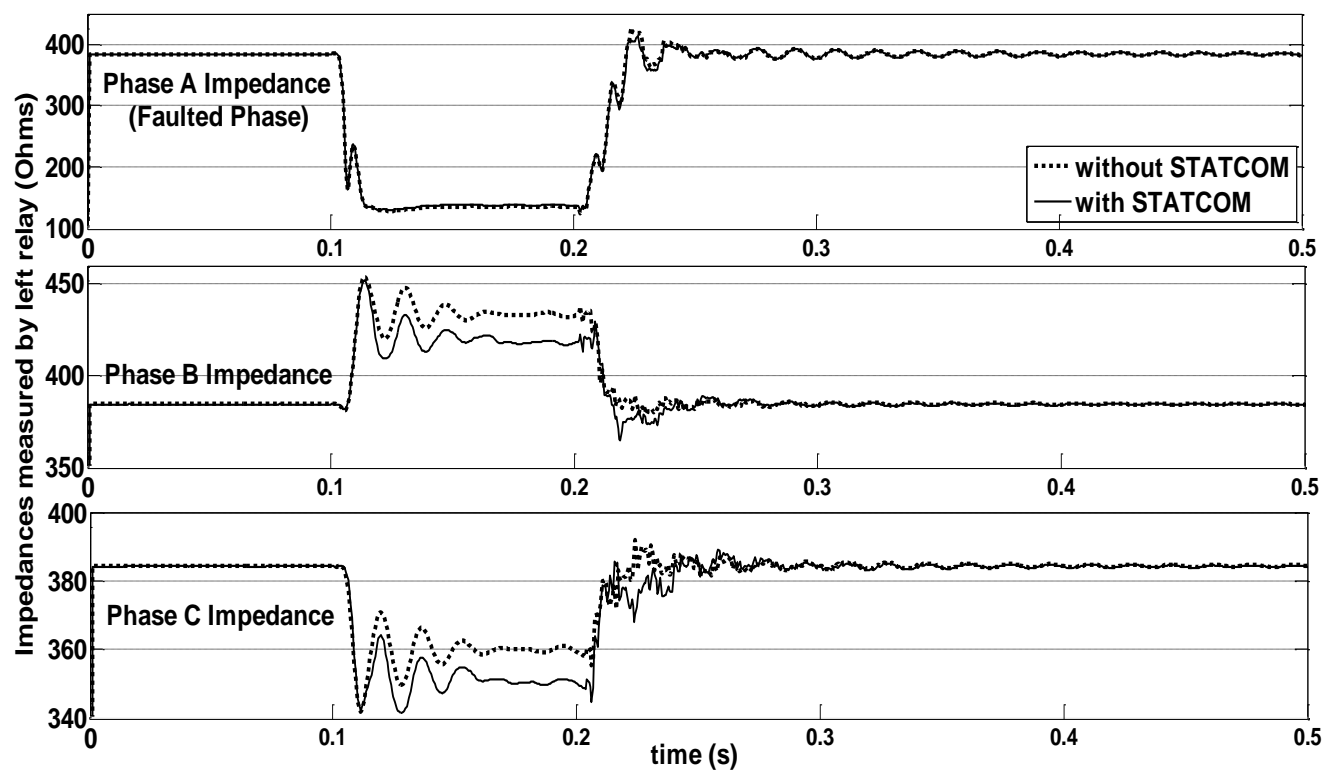

(a)

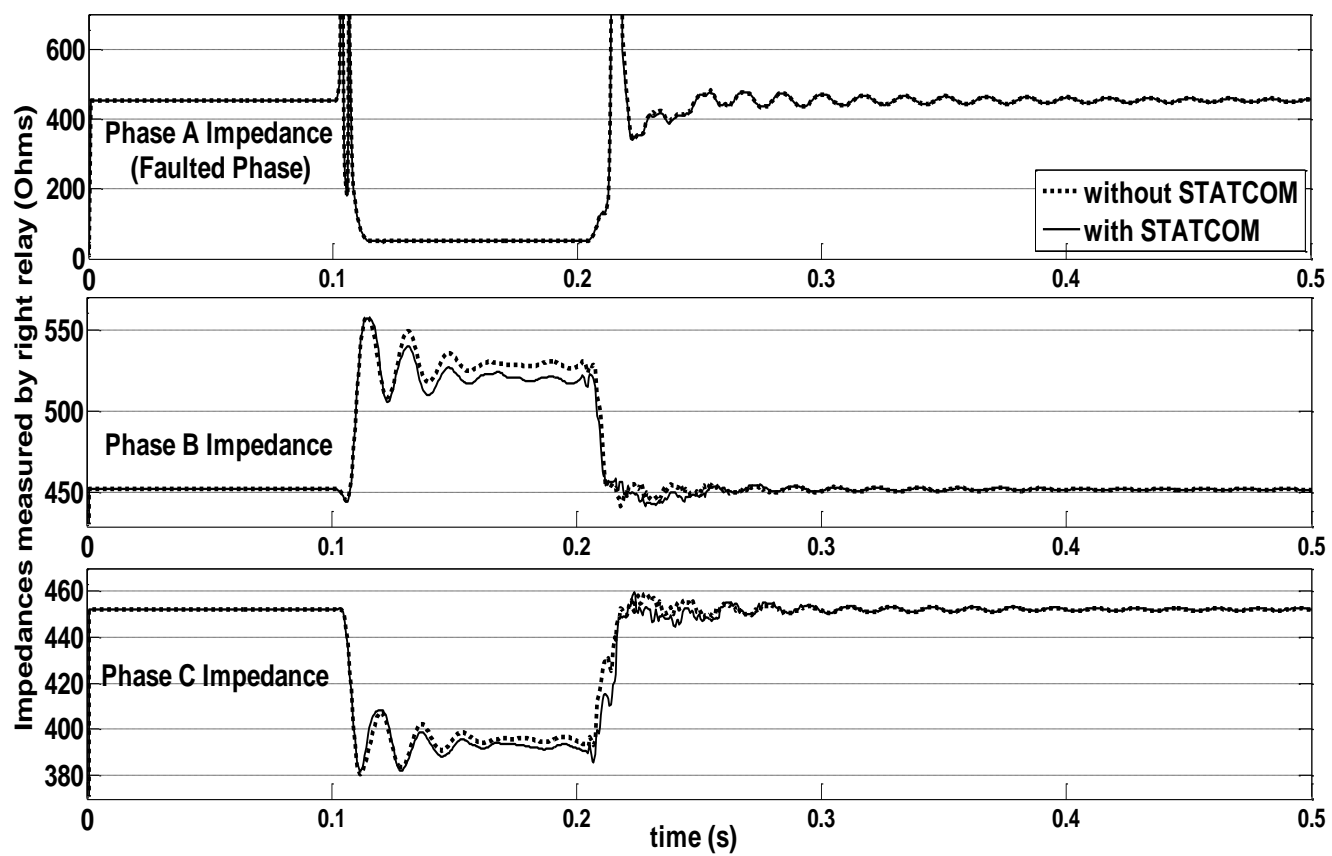

(b)

Fig. (12) Transmission line impedance in case of single phase to ground fault (a) Impedances measured by left relay (b) Impedances measured by right relay 


\section{REFERENCES}

1. B. Ram, Power system protection and switchgear, McGraw-Hill, 1995.

2. M. S. Sachdev, R. Das, "Understanding microprocessor-based technology applied to relaying", Power system relaying committee, Report of working group 116 and the relaying practices subcommittee, 2004.

3. S. Panda, R. N. Patel, "Improving power system transient stability with an offcentral location of shunt FACTS devices", Journal of electrical engineering, vol. 57, no. 6, 2006, pp. 365-368.

4. E. Uzunovic, C. Canizares, J. Reeve, "Fundamental frequency model of static synchronous compensator", North American Power Symposium (NAPS), Laramie, Wyoming, 1997, pp. 49-54.

5. N. G. Hingorani, L. Gyugyi, "Understanding FACTS; Concepts and technology of flexible AC transmission system", IEEE Press book, 2000.

6. M. Benghanem, A. Draou, "A new modelling and control analysis of an advanced static var compensator using a three level (NPC) inverter topology", Journal of electrical engineering, vol. 57, no. 5, 2006, pp. 285-290.

7. G. Sybille, P. Giroux, "Simulation of FACTS controllers using the MATLAP power system blockset and hypersim real-time simulator", IEEE Power engineering society winter meeting, vol. 1, 2002, pp. 488-491.

8. C. Schauder, et al, "AEP UPFC project: installation, commissioning and operation of the \pm 160 MVA STATCOM (phase I)", IEEE Transactions on power delivery, vol. 13, issue: 4, 1998, pp. 1530-1535.

9. K. El-Arroudi, G. Jooos, D. T. McGillis, "Operation of impedance protection relays with the STATCOM", IEEE Transactions on power delivery, vol. 17, no. 2, 2002, pp. 381-387.

10. M. Khederzadeh, "The impact of FACTS devices on digital multifunction protective relays", IEEE conference and exhibition on transmission and distribution, Asia pacific IEEE/PES, vol. 3, 2002, pp. 2043-2048. 


\section{عمل الوقاية الرقمية المعتمدة علي قياس المعاوقة مع انظمة نقل القوى المرنة ذات معوضات القدرة الاستاتيكة المتزامنة}

يقدم هذا البحث دراسة التاثيرات لأنظمة نقل القوب المرنة ذات معوضات القدرة الاستاتيكية المتزامنة علي

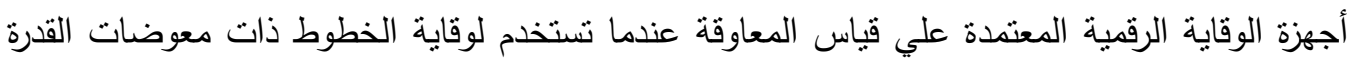
الموصلة بالتوازي. إن أغلب معدات نقل القوى المرنة يتم نركبيها علي خطوط نقل تعمل من قبل وذلكانك لتحسين قدرتها وخواصها. أن معوض القدرة الإستاتيكي المتزامن يعتبر احدي مكونات خطوط النقائل المرنة حيث انه يستخدم اليكترونيات القوى في التحكم في نسبة سريان الطاقة وتحسين أتزان الثبكة

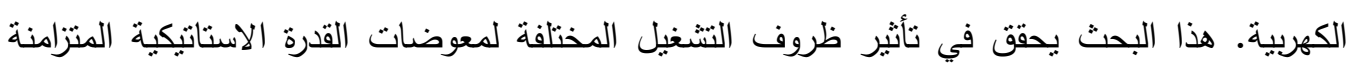
أثثاء نأرجح الجها وأثناء حدوث قصر علي قيمة المعاوقة المقاسة بمتابع الوقاية الرقمي ـ نم استخدام

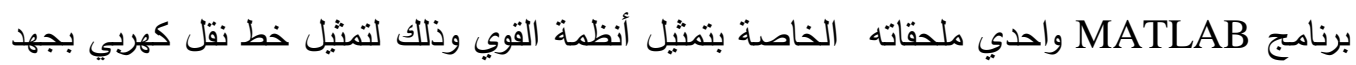
500 كيلو فولت وطول 300 كيلو متر ومركب علية معوض قدرة. تم دراسة كل أنواع القصر وكذلك فئل حالات تأرجح جهد الخط علي الوقاية الرقمية المعتدة علي المعاوقة في حالة أن يكون الخط موصلاً

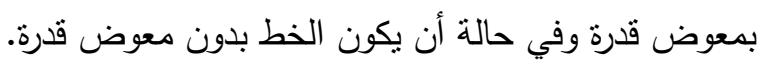

